Www.jmscr.igmpublication.org

Index Copernicus Value: 79.54

ISSN (e)-2347-176x ISSN (p) 2455-0450

crossref DOI: https://dx.doi.org/10.18535/jmscr/v7i5.132

\title{
Study of Morphological and Morphometric Features of Suprascapular Notch in Human Dry Scapulae at S.M.S. Medical College Jaipur
}

\author{
Authors \\ Rajoria Sushil Raj ${ }^{1}$, Agarwal Chandra Kala ${ }^{2}$, Chauhan Sangita ${ }^{3 *}$, \\ Yadav Vishva Deepak ${ }^{4}$ \\ ${ }^{1,4}$ Postgraduate Student, ${ }^{2,3}$ Sr. Professor \\ Department of Anatomy, S.M.S. Medical College, Jaipur, Rajasthan, India \\ *Corresponding Author \\ Chauhan Sangita \\ Sr. Professor, Department of Anatomy, S.M.S. Medical College, Jaipur, Rajasthan, India
}

\begin{abstract}
Introduction: Suprascapular notch (SSN) is a depression present on the superior border of scapula just medial to root of coracoid process. This notch is an important landmark in arthroscopic shoulder operations for the suprascapular nerve. The aim of present study was to classify the suprascapular notch in various types and to study morphological variations of it.

Materials and Methods: The study was conducted on dried, unbroken and completely ossified human scapulae obtained from Department of Anatomy, SMS Medical College and RUHS Medical College, Jaipur (Rajasthan) from February 2017 to January 2018. The suprascapular notch was classified on the basis of two classifications proposed by Natsis et al and Iqbal et al. Percentage of each type, the vertical depth, the maximum transverse diameter of the suprascapular notchand distance from supraglenoid tubercle to the base of the notchwere measured and compared with the previous studies.

Results: The suprascapular notch was present in 98\% bones. The mean vertical depth was $11.54 \mathrm{~mm}(1.02-$ $13.0 \mathrm{~mm})$, transverse diameter was $14.04 \mathrm{~mm}(0.86-21.26 \mathrm{~mm})$ and distance from supraglenoid tubercle to the base of the notch was $29.12 \mathrm{~mm}(25.46-38.70 \mathrm{~mm})$. It was classified according to Natsis et al classification into type-I (2\%), type-II (76\%) type-III (20.4\%) type-IV (1.6\%) and type-V (0\%).

Conclusion: The present study provided the data related to various types and anatomical variations of suprascapular notch which may be useful for clinicians to associate them with suprascapular nerve entrapment.
\end{abstract}

Keywords: Scapula, Scapular notch, Vertical diameter, Transverse diameter.

\section{Introduction}

Suprascapular notch (SSN) is a depression present on the superior border of scapula just medial to root of coracoid process. ${ }^{1}$ This notch is converted into a foramen by the superior transverse scapular ligament (STSL). This foramen transmits the suprascapular nerve to the supraspinous fossa, whereas the suprascapular vessels pass above the ligament. The suprascapular nerve has a tortuous course from the supraspinous fossa to the infraspinous fossa through spinoglenoid notch. It supplies supraspinatus and infraspinatus muscles 
as well as sensory branches to the shoulder and acromioclavicular joint. ${ }^{1-2}$

Koppel and Thompson ${ }^{3}$ (1959) were the first to describe the suprascapular nerve entrapment syndrome, which causes shoulder pain in approximately $1-2 \%$ population. It manifests as weakness of the arm, difficulty in external rotation and abduction and later on atrophy of supraspinatus and infraspinatus muscles. It is most commonly seen in volleyball players, athletes, baseball players, weight lifters, tennis players, fencers, hunters and people in occupations requiring overhead work, that is, extreme abduction and external rotation. ${ }^{4-5}$

This notch is an important landmark in arthroscopic shoulder operations for the suprascapular nerve. ${ }^{6}$ The anatomical variation of the suprascapular notch, which includes the variation in shape, complete or partial ossification of the superior transverse scapular ligament, is recognized as one of the causes of suprascapular nerve entrapment. Suprascapular notch has been classified by various workers in different populations on the basis of parameters such as vertical depth of the notch, maximum transverse diameter of the notch and shape of the notch. ${ }^{7-8}$

Natsis et $\mathrm{al}^{7}$ classified the suprascapular notch into the following five types; type-I (without a discrete notch), type-II (notch with maximum transverse diameter), type-III (notch with maximum vertical diameter), type-IV (bony foramen) and type-V (a notch and a bony foramen).

Iqbal et $\mathrm{al}^{8}$ reported three types of suprascapular notch based on its shape ' $U$ ', ' $V$ ',' J' on gross examination. In the present study, the suprascapular notches were classified on the basis of classification given by Natsis et $\mathrm{al}^{7}$ and Iqbal et $\mathrm{al}^{8}$. The aim of present study was to study morphological and morphometric variations of suprascapular notch in bones present in Anatomy Department of SMS Medical College and RUHS Medical College, Jaipur which may be useful for clinicians to associate them with suprascapular nerve entrapment.

\section{Material and Methods}

It was a cross sectional descriptive study which wascarried out in Anatomy Departments of SMS Medical College and RUHS Medical College, Jaipur (Rajasthan) from February 2017 to January 2018. After taking prior approval from institutional ethics committee and head of departments of both institutes 250 dried, unbroken and completely ossified human scapulae of unknown age and sex were taken. Selected scapulae were labelled from 1 to 250 and right and left. Different morphological features of suprascapular notches were noted and morphometric measurements were done.

The data collected were entered in Microsoft Excel 2010 Spreadsheets and analyzed. Results were expressed as percentages and proportions for qualitative data while as mean was calculated for quantitative data.

\section{Results}

Out of 250 human scapulae, 141 (56.4\%) were of left side and 109 (43.6\%) were of right side. On examination of scapulae for presence or absence of notch and after taking measurements, 5 different types were classified (Natsis et $\mathrm{al}^{7}$ classification). The morphometric data of suprascapular notch measured were vertical depth (VD), maximum transverse diameter (MTD) and distance from supraglenoid tubercle to the base of the suprascapular notch. There were 5 scapulae (2\%) without a discrete notch and they were considered as type-I. The rest 245 (98\%) scapulae showed the other four types. Type-II in which the transverse diameter of the notch was longer than the vertical diameter (MTD>VD) was present in 194 scapulae $(76 \%)$. Type-III was present in 51 (20.4\%) and had VD>MTD. Type-IV with suprascapular foramen only without a visible notch was found in 4 scapulae (1.6\%) and type-V i.e. presence of both notch and foramen together in the same scapula was not observed in this study (Table-1).

According to Iqbal et $\mathrm{al}^{8}$ classification (Table-2), the most common type of supra scapular notch 
found was U-shaped (55.2\%) (Figure-1), followed by J-shaped (27.2\%3) (Figure-2) and V-shaped $(11.6 \%)$ (Figure-3). 6 scapulae (2.4\%) had indentation (Figure-4) along the superior border while complete ossification of STSL was found in $4(1.6 \%)$ scapulae (Figure-5). In 5 scapulae (2\%) there was no notch (Figure-6).

In the present study, the mean maximum transverse diameter (MTD) was $14.04 \mathrm{~mm}$ (range $=0.86-21.26 \mathrm{~mm})$. On the right side, it was $11.39 \mathrm{~mm}$ (range $=0.86-21.26 \mathrm{~mm}$ ) whereas on the left side, it was $9.29 \mathrm{~mm}$ (range $=2.42-13.84$ $\mathrm{mm}$ ). Thus, it was higher on the right side than the left side. The mean vertical depth (VD) was 11.54 $\mathrm{mm}$ (range $=1.02-13.0 \mathrm{~mm}$ ). On the right side, it was $5.94 \mathrm{~mm}($ range $=1.02-13.0 \mathrm{~mm})$ whereas on left side, it was $8.28 \mathrm{~mm}$ (range $=1.36-11.38 \mathrm{~mm}$ ) and it was higher on the left side. The mean distance from the base of suprascapular notch to the supraglenoid tubercle was $29.12 \mathrm{~mm}$ (range= 25.46-38.7 mm). On the right side, it was 29.69 $\mathrm{mm}$ (range $=25.46-38.7 \mathrm{~mm}$ ) whereas on the left side, it was $29.85 \mathrm{~mm}$ (range $=26.4-38.7 \mathrm{~mm}$ ). Thus, it was slightly higher for the left side than the right side (Table-3).

Table-1: Distribution of suprascapular notch according to Natsis et $\mathrm{al}^{7}$ classification

\begin{tabular}{|l|c|c|c|}
\hline Types & Description & Number (n) & Percentage (\%) \\
\hline Type I & Without a discrete notch & 5 & 2 \\
\hline Type II & (MTD> VD) & 190 & 76 \\
\hline Type III & (MTD< VD) & 51 & 20.4 \\
\hline Type IV & Bony foramen & 4 & 1.6 \\
\hline Type V & Bony foramen and notch & 0 & 0 \\
\hline
\end{tabular}

Table-2: Distribution of supra scapular notch according to shape (Iqbal et $\mathrm{al}^{8}$ classification)

\begin{tabular}{|l|l|c|c|}
\hline S. No. & Shape & Number (n) & Percentage (\%) \\
\hline 1 & Absence of notch & 5 & 2 \\
\hline 2 & U-shape & 138 & 55.2 \\
\hline 3 & V-shape & 29 & 11.6 \\
\hline 4 & J-shape & 68 & 27.2 \\
\hline 5 & O-shape foramen or completely ossified & 4 & 1.6 \\
\hline 6 & Indentation & 6 & 2.4 \\
\hline 7 & $\begin{array}{l}\text { The partial ossification of the STSL converting the notch } \\
\text { into a complete bony foramen }\end{array}$ & 0 & 0 \\
\hline
\end{tabular}

Table-3: Comparison of various parameters of supra scapular notch

\begin{tabular}{|l|c|c|c|c|c|c|}
\hline \multirow{2}{*}{ Parameter } & \multicolumn{3}{|c|}{ Mean (mm) } & \multicolumn{3}{c|}{ Range (mm) } \\
\cline { 2 - 7 } & Right & Left & Both & Right & Left & Both \\
\hline Vertical depth (VD) & 5.94 & 8.28 & 11.54 & $1.02-13.0$ & $1.36-11.38$ & $1.02-13.0$ \\
\hline $\begin{array}{l}\text { Maximum transverse diameter } \\
\text { (MTD) }\end{array}$ & 11.39 & 9.29 & 14.04 & $0.86-21.26$ & $2.42-13.84$ & $0.86-21.26$ \\
\hline $\begin{array}{l}\text { Distance from supraglenoid } \\
\text { tubercle to the base of the notch }\end{array}$ & 29.69 & 29.85 & 29.12 & $25.46-36.54$ & $26.4-38.7$ & $25.46-38.7$ \\
\hline
\end{tabular}




\section{JMSCR Vol||07||Issue ||05||Page 820-826||May}

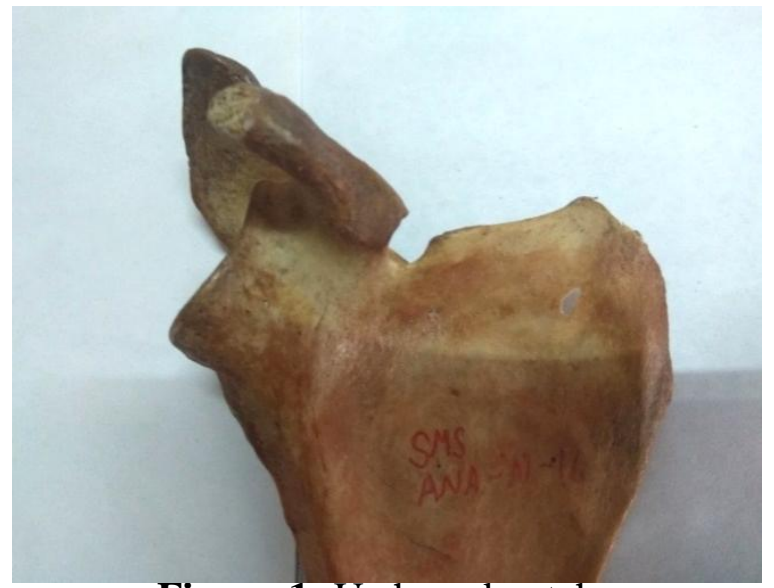

Figure-1: U-shaped notch

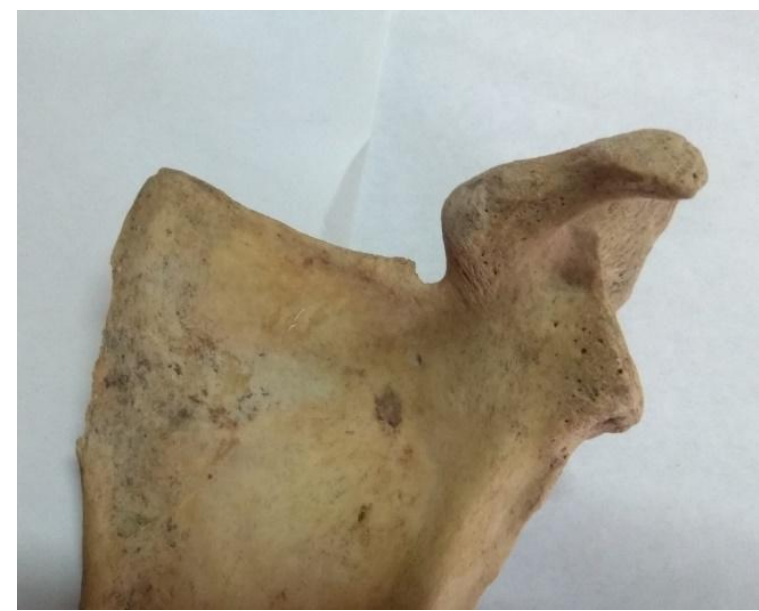

Figure-3: J-shaped notch

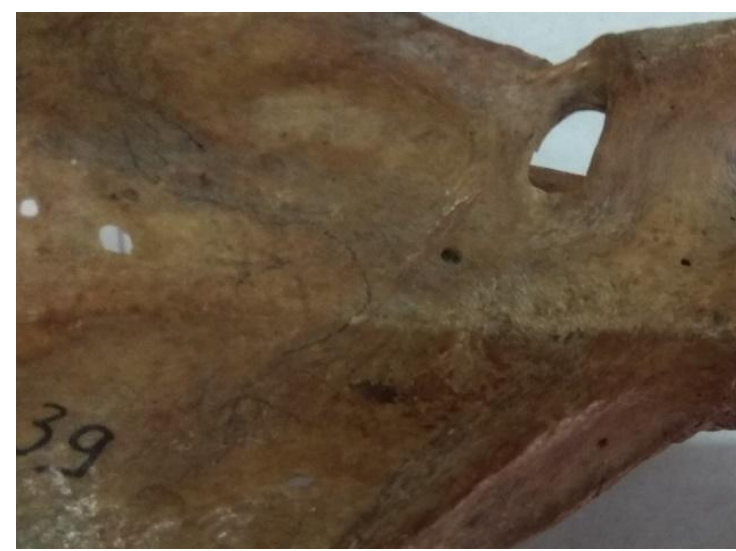

Figure-5: Complete ossification of notch (O-shaped)

\section{Discussion}

The suprascapular notch is a feature of superior border of every scapula. Several morphological variations and classifications of suprascapular notch have been studied in various populations of world. The knowledge of variations of the shape of suprascapular notch is also essential in various techniques associated with arthroscopic

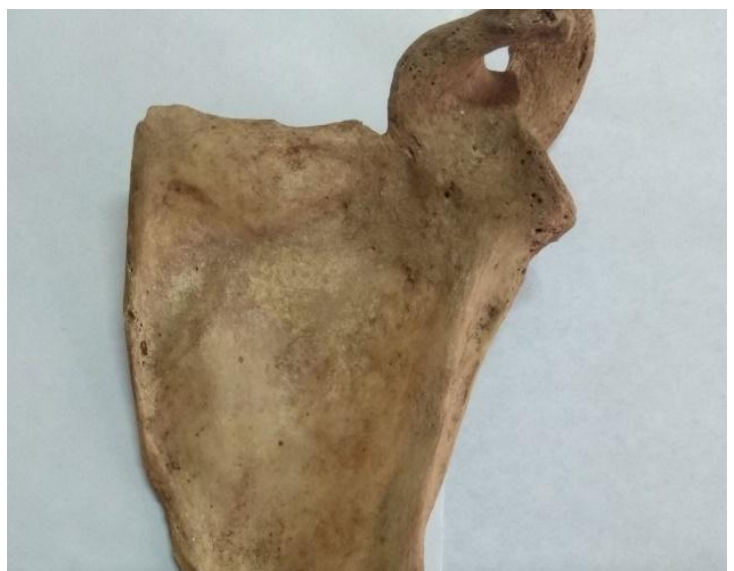

Figure-2: V-shaped notch

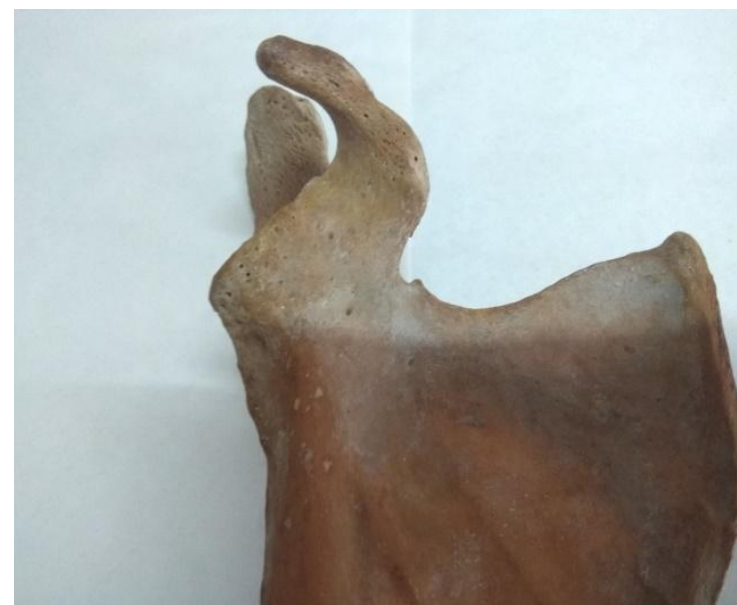

Figure-4: Notch with Indentation

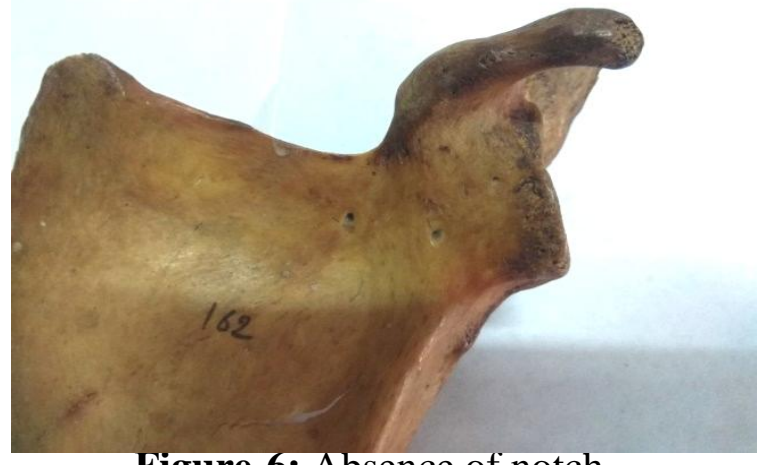

Figure-6: Absence of notch

suprascapular nerve decompression. The analysis of literature given by various authors, different classifications were used to study morphology and morphometry of the suprascapular notch. ${ }^{7-11}$

The classification given by Rengachary et a ${ }^{10}$ was difficult to use when transition between types is being found. The classification given by Natsis et $\mathrm{al}^{7}$ seems to be simple and includes all the 
anatomical variations based on the vertical and transverse diameters of the suprascapular notch. The classification by Iqbal et $\mathrm{al}^{8}$ though provides an easy method of distinction of suprascapular notch based on its shape (U, V and J) without involving any measurements but some notches do not had any of the three mentioned shapes. As the other shapes of notch also observed were wide notch, shallow $U$ and hockey stick shapes are not included in the classification given by Iqbal et al. The results of the present study showed that the most common type of suprascapular notch was
type-II (77.6\%) and the least common was typeIV (1.6\%). Type-V was absent in the present study. The findings were consistent with previous studies done by Soni et $\mathrm{al}^{12}$ and Sutheria et $\mathrm{al}^{13}$ in Indian population, Mahdy et $\mathrm{al}^{14}$ in the Egyptian and Wang et $\mathrm{al}^{15}$ in Chinese population, where also the most common was type-II and least common was type-V. Natsis et $\mathrm{al}^{7}$ in their study reported an equal incidence of type-II and type-III suprascapular notch.

Table-4: The frequencies of various types of suprascapular notch in different populations using the classification given by Natsis et $\mathrm{al}^{7}$

\begin{tabular}{|c|c|c|c|c|c|c|}
\hline Study & Population & Type I & Type II & Type III & Type IV & Type V \\
\hline Present study 2018 & Indian & $2 \%$ & $77.6 \%$ & $20.4 \%$ & $1.6 \%$ & $0 \%$ \\
\hline Soni et al $^{12} 2012$ & Indian & $5 \%$ & $72 \%$ & $20 \%$ & $3 \%$ & $0 \%$ \\
\hline Sutheria et $\mathrm{al}^{13} 2013$ & Indian & $6.06 \%$ & $45.45 \%$ & $43.93 \%$ & $3.03 \%$ & $1.50 \%$ \\
\hline Mahdy et $\mathrm{al}^{14} 2013$ & Egyptian & $6.06 \%$ & $45.45 \%$ & $43.93 \%$ & $3.03 \%$ & $1.50 \%$ \\
\hline Wang et al ${ }^{15} 2011$ & Chinese & $28 \%$ & $58.16 \%$ & $28.23 \%$ & $3 \%$ & $0 \%$ \\
\hline Natsis et $\mathrm{al}^{7} 2007$ & Greek & $8.30 \%$ & $41.85 \%$ & $41.85 \%$ & $7.30 \%$ & $0.70 \%$ \\
\hline
\end{tabular}

In the present study, out of 250 scapulae, 138 (55.2\%) had U-shaped suprascapular notch with approximately parallel sides and a rounded base. $68(27.2 \%)$ scapulae had J-shaped notch with one side short and another side long. 29 (11.6\%) scapulae had $\mathrm{V}$-shaped notch with convergence of two sides toward a narrow base. According to Iqbal et $\mathrm{al}^{8}$, U-shaped notches were $13.2 \%$, Vshaped notches were $20 \%$, J-shaped notches were $22 \%$ and 45 out of 200 scapulae are without suprascapular notch in the population of Pakistan. Other studies done by Ticker et $\mathrm{al}^{11}$, Soni $\mathrm{G}$ et al ${ }^{12}$ and Sutaria et $\mathrm{al}^{13}$, the most common type of notch was U-shaped in Indians, whereas in Kenyans, hockey stick shaped and in Pakistanis, J-shaped notch was found to be most common. In the present study, 5 (2\%) scapulae were not had any suprascapular notch. $6(2.4 \%)$ scapulae showed indentation. In a case report by Rekha ${ }^{16}$, occasional absence of suprascapular notch was observed. In the present study, $4(1.6 \%)$ had complete ossification of superior transverse scapular ligament. Complete ossification leads to the formation of suprascapular foramen. Iqbal et $\mathrm{al}^{8}$ did not mention about the ossification of transverse scapular ligament and foramen. In the study done by Patel et $\mathrm{al}^{17}, 3.75 \%$ scapulae showed suprascapular foramen due to complete ossification of transverse scapular ligament. Most common radiological finding in suprascapular nerve entrapment syndrome is shallowness and deformity of the suprascapular notch.

In the present study, coexistence of suprascapular foramen and suprascapular notch was not observed. In the study done by Natsis et $\mathrm{al}^{7}$ occasional coexistence of suprascapular notch and suprascapular foramen were observed due to the complete ossification of superior transverse scapular ligament (STSL) which is a potential risk factor in the occurrence of suprascapular nerve entrapment.

The differences in morphology of the suprascapular notch can be explained by the fact that the shape of the suprascapular notch is influenced by the ossification of coracoid process. Variation in the morphology of the STSL which include their partial or complete ossification have been identified to be one of the important 
predisposing factor in cases of suprascapular nerve entrapment in various case reports.

The size of the suprascapular notch is also thought to play a part in the predisposition for suprascapular nerve entrapment, assuming that a small notch gives a larger chance of nerve impingement than a large notch. In the present study the most common type of notch observed is type-II (MTD>VL), where the chances of suprascapular nerve entrapment would be less. In type-III, IV and V the chances of suprascapular nerve entrapment would be more.

In open surgical procedure, Warner et $\mathrm{al}^{18}$ and De Mulder et $\mathrm{al}^{19}$ found that the distance between margins of glenoid cavity and suprascapular notch was very critical. A safe zone was explained by them to avoid damage to the suprascapular nerve during the surgeries around the areas. These distances were $1.4 \mathrm{~cm}$ posterior border of glenoid just at the base of spine of scapula and $2.3 \mathrm{~cm}$ from glenoid just at the upper rim of glenoid. Therefore, surgeons must aware about this safe zone during surgical procedures to minimize the risk of iatrogenic injury of the suprascapular nerve.

\section{Conclusion}

Knowledge of anatomical variations of suprascapular notch is useful for clinicians for clear and early diagnosis of suprascapular nerve entrapment syndrome. These variations should be kept in mind during surgical or arthroscopic shoulder procedures to prevent iatrogenic supra scapular nerve injuries.

\section{References}

1. Standring S, Ellis H, Healy JC, Johnson D, Williams A, Collins $\mathrm{P}$ et al. Gray's Anatomy. In: Pectoral Girdle and Upper Limb. Johnson D Horold Ellis, editors. $39^{\text {th }}$ ed. Edinburg, London: Churchill Livingstone; 2005. P. 819-22.

2. Moore KL, Dalley AF and Agur AM. Clinical Oriented Anatomy. $6^{\text {th }}$ ed.
Philadelphia: Lippincotiliams\& Wilkins; 2010.

3. Koppel HP, Thompson WA. Pain and the frozen shoulder. Surg Gynecol Obstet. 1959;109:92-6.

4. Antonoiou J, Tae SK, Wiliams GR, Bird S, Ramsey MJ, Iannotti JP. Suprascapular neuropathy: Variability in the diagnosis, treatment, and outcome. Clin OrthopRel Res. 2001;386:131-8.

5. Edeland HG, Zachrisson BE. Fracture of the scapular notch associated with lesion of the suprascapular nerve. Acta Orthop Scand. 1975;46(758):763.

6. Shishido $H$, Kikuchi $S$ Injury to the suprascapular nerve during shoulder joint surgery: an anatomical study. J Shoulder Elbow Surg. 2001;10:372-376.

7. Natsis K, Totlis T, Tsikaras P, Appell HJ, Skandalakis K. Proposal for classification of the suprascapular notch: a study on 423 dried scapulas. ClinAnat. 2007; 20(2):1359.

8. Iqbal K, Iqbal R, Khan SG. Anatomical variations in shape of suprascapular notch of scapula. J Morphol Sci. 2010;27:1-2.

9. Polguj M, Jedrzejewski K, Podgórski M, Topol M. Correlation between morphometry of the suprascapular notch and anthropometric measurements of the scapula. Folia Morphol. 2011;70(2):10915.

10. Rengachary SS, Neff JP, Singer PA, Brackett CF. Suprascapular nerve entrapment neuropathy: A clinical, anatomical and comparative study. Neurosurg. 1979;5:441-6.

11. Ticker JB, Djurasovic M, Strauch RJ, April EW, Pollock RG, Flatow EL, Bigliani LU. The incidence of ganglion cysts and other variations in anatomy along the course of the suprascapular nerve. J Shoulder Elbow Surg. 1998;7:472-478. 
12. G Soni, V Malik, L Shukla, S Chabbra, N Gaur. Morphometric Analysis of the Suprascapular Notch. The Internet Journal of Biological Anthropology. 2012;5(1):15.

13. Sutheria LK, Nayak TV, Patel SV, Jadav HR, Pensi CA. Morphology and morphometric analysis of suprascapular notch. Int $\mathrm{J}$ Biomed Advance Res. 2013;4:35-39.

14. Mahdy A A, Shehab A A. Morphometric Variations of the Suprascapular Notch as a potential cause of Neuropathy. Anatomical Study J Am Sci. 2013;9:189-97.

15. Wang H, Chen C, Wu L, Pan C, Zhang W, Li Y. Variable morphology of the suprascapular notch: an investigation and quantitative measurements in Chinese population. Clin Anat. 2011;24(1):47-55.

16. Rekha BS. Complete absence of suprascapular notch- a case report. Journal of Evolution of Medical and Dental Sciences. 2013;2(1):19-22.

17. Patel P, Patel SV. Study of variations in the shape of suprascapular notch in dry human scapula. Int J Biomed Res. 2013; 4:3162-4.

18. Warner JJP, Krushell RJ, Masquelet A, Gerber C. Anatomy and relationships of suprascapular nerve: anatomical constraints to mobilization of the supraspinatus and infraspinatus muscles in management of massive rotator-cuff tears. J Bone Joint Surg Am. 1992; 74: 36-45.

19. De Mulder K, Marynissen H, Van Laere C. Arthroscopic transglenoid suture of Bankart lesions. Acta Orthop Belg. 1998; 64 160-66. 